\title{
Quadro citológico vaginal, concentração plasmática de progesterona durante a gestação e medidas fetais em paca (Cuniculus paca Linnaeus, 1766)
}

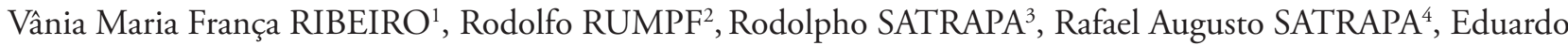 \\ Montanari RAZZA5, José Marques CARNEIRO JUNIOR ${ }^{6}$, Maria do Carmo PORTELA ${ }^{7}$
}

\begin{abstract}
RESUMO
Em 27 pacas (Cuniculus paca Linnaeus, 1766) objetivou-se descrever aos 30, 60 e 90 dias (D) de prenhez diagnosticada por ultrassonografia (US), os tipos celulares do epitélio vaginal em esfregaços vaginais, relatar as condiçóes de abertura da vulva e as características do muco vaginal, determinar a concentração plasmática de progesterona (P4) por radioimunoensaio, e ainda, mensurar por ultrassonografia (US) o diâmetro biparietal (DBP) fetal aos 60 e 90 dias de prenhez. No D30, 40\% das amostras exibiram células (com características estrogênicas) superficiais e presença de núcleos nus. Nos D60 e D90, células parabasais, intermediárias, superficiais e naviculares estavam presentes nas mesmas proporçôes, mas células endocervicais foram descritas em apenas 73,9\% e 69\% das amostras daqueles dias, respectivamente. No D30 a maior proporção de células naviculares e superficiais diferiu $(\mathrm{p}<0,05)$ em relação aos outros tipos celulares presentes. $\mathrm{O}$ muco vaginal apresentou-se cristalino e fluido em $100 \%$ e em $70 \%$ das fêmeas nos D30 e D60, respectivamente. Observou-se o vestíbulo vaginal aberto em torno de $50 \%$ das fêmeas em todos os dias de exames. Valores mínimos detectáveis de P4 foram obtidos em $72 \%$ e em $83 \%$ das fêmeas, enquanto que as médias das medidas dos DBP foram $1,25 \mathrm{~cm}( \pm 0,16)$ e 2,34 cm $( \pm 0,25)$ nos D60 e D90, respectivamente. O quadro citológico vaginal nos D30, D60 e D90 e o DBP fornecem elementos que contribuem para diagnóstico de gestação em pacas. A concentração de $\mathrm{P} 4$ demonstra a necessidade de maiores estudos da endocrinologia da gestação em pacas.
\end{abstract}

PALAVRAS CHAVE: Prenhez em paca, diâmetro biparietal, progesterona, animais silvestres, região amazônica.

\section{Vaginal citology, serum progesterone concentration during pregnancy and fetal measurements in paca (Cuniculus paca, Linnaeus 1766)}

\begin{abstract}
The objective of this work was to describe in 27 pacas (Cuniculus paca Linnaeus, 1766) at 30, 60 and 90 days (D) of pregnancy diagnosed by ultrasonography (U.S.) the cell types of the vaginal epithelium by vaginal smears, to report the vulva opening condition and the characteristics of vaginal mucus, to determine the progesterone (P4) serum concentration by radioimmunoassay, and also measure by ultrasound (U.S.) the fetuses biparietal diameter (BPD) at 60 and 90 days of pregnancy. At D30, 40\% of the smears exhibited surface cells (with estrogenic characteristics) and of naked nuclei. At D60 and D90, parabasal, intermediate, superficial, and navicular cells were present in the same proportions, but endocervical cells were described in only $73.9 \%$ and $69 \%$ of those day's smears, respectively. At D30 the highest proportion of navicular and surface cells differed $(\mathrm{p}<0.05)$ compared with other cell types. The vaginal mucus was crystalline and fluid in 100\% and $70 \%$ of females at D30 and D60, respectively. It was observed the vaginal vestibule open in around 50\% of females in every day of exams. Minimum detectable P4 serum concentration was obtained on $72 \%$ and $83 \%$ of females, while the averages of the BPD were $1.25 \mathrm{~cm}( \pm 0.16)$ and $2.34 \mathrm{~cm}( \pm 0.25)$ on D60 and D90, respectively. Vaginal cytology aspects at D30, D60 and D90 and BPD provide elements to contribute to pregnancy diagnosis in paca. P4 concentration shows the need of further endocrinology of pregnancy studies of paca.
\end{abstract}

KEYWORDS: Pregnancy in paca, biparietal diameter, progesterone, wild animal, Amazon region.

\footnotetext{
1 Universidade Federal do Acre, BR-364, km 4, Rio Branco-Acre, Brasil. Email: vania.rib@uol.com.br

2 Empresa Brasileira de Pesquisa Agropecuária/CENARGEN, SAIN Parque Rural, W5 Norte Final, Asa Norte Brasília, DF, Brasil. Email: rodolfo@cenargen.embrapa.br

3 Universidade Federal do Acre, BR-364, km 4, Rio Branco-Acre, Brasil Email: rsatrapa@uol.com.br

${ }^{4}$ Instituto de Biociências, Distrito de Rubião Junior s/n. UNESP/Botucatu, São Paulo, Brasil. Email: rsatrapa@yahoo.com.br

${ }^{5}$ Instituto de Biociências, Distrito de Rubião Junior s/n. UNESP/Botucatu, São Paulo, Brasil. Email: eduardorazza@gmail.com

${ }^{6}$ Empresa Brasileira de Pesquisa Agropecuária, BR 364, km 14,Rio Branco, Acre, Brasil. Email: marques@cpafac.embrapa.br

Secretaria de Estado de Agropecuária. Rua do Aviário, 315, Rio Branco - Acre. E-mail: mdportela@uol.com.br
} 


\section{INTRODUÇÃO}

A paca tem sido utilizada como fonte de proteína na alimentaçấo dos povos da floresta e de produtores rurais da regiáo neotropical, mas a caça indiscriminada nas reservas extrativistas poderá provocar esgotamento populacional desta e de outras espécies (Mittermeier et al. 1992; IBAMA 2003). Portanto, a criação em cativeiro se apresenta como uma alternativa à exploração econômica e sustentável desta espécie.

Na natureza, são animais de hábitos solitários, com pares de adultos vivendo em uma área de aproximadamente 2,5 ha em média, defendida contra invasores (Moreira e Macdonald 1997). Em cativeiro, normalmente um macho pode conviver com três a cinco fêmeas em uma baia com $12 \mathrm{~m}^{2}$ (Hosken e Silveira 2001; Ribeiro e Zamora 2008).

Pacas reproduzem-se o ano todo (Nogueira Filho e Nogueira 1999; Ribeiro e Zamora 2008) e seu período gestacional é citado na literatura com grandes variaçóes como desde 97 dias (Matamoros 1982) até 155 dias (Rengifo et al. 1996).

A cópula em geral ocorre à noite e um achado póscópula é o tampão vaginal de sangue e sêmen que é expulso e pode ser ingerido pela fêmea (Hosken e Silveira 2001). Estes autores relatam que por serem muito susceptíveis às condições ambientais a que estão submetidas em cativeiro, as pacas apresentam certas variaçôes em alguns parâmetros reprodutivos.

A citologia vaginal tem sido empregada para identificar as fases do ciclo estral em pacas (Matamoros e Pashov 1984; Nogueira et al. 2005; Guimarães et al. 2008). Por ser constituído por camadas morfologicamente distintas, o epitélio vaginal é alterado de acordo com o estímulo hormonal predominante em cada fase, as quais podem ser identificadas através de métodos apropriados de coloração histológica (Raposo et al. 2000; Porto 2007). Assim, em pacas, diversos autores (Matamoros e Pashov 1984; Nogueira et al. 2005; Pérez e Baz 2006, Guimarães et al. 2008) identificaram em um ciclo estral de cerca de 32,5 $\pm 3,69$ dias, diferentes fases como: proestro, estro, metaestro e diestro.

A influência da gravidez sobre os epitélios do útero, da cérvix e da vagina é bastante acentuada (Carvalho 2002) e, no seu decurso, a citologia vaginal é caracterizada pela ausência das variaçóes cíclicas motivada pela progressiva acentuação da estimulaçáo hormonal do tipo progestacional (Gompel e Koss 1997).

Diehl e Day (1973) afirmam que a quantidade de camadas do epitélio vaginal é um critério utilizado, entre vários, para distinguir prenhez de não prenhez; assim, o encontro de duas a três camadas apenas de epitélio vaginal pode ser considerado prenhez.
Durante a prenhez, a concentraçáo de progesterona no plasma das espécies hystricomorphas (subordem dos roedores) pode ser dividida em duas fases: níveis hormonais baixos e altos (Busso, et al. 2007).

Em chinchilas (Chinchila laninger Gray, 1831) de acordo com Tam (1970) e Busso et al. (2007), durante os primeiros 40 dias de prenhez a progesterona no plasma permanece sem mudanças relevantes, mas a partir dos 60 dias, o conteúdo hormonal alcança altos valores e assim se mantém. Gromadzka-Ostrowska et al. (1985) relatam que nesta espécie, conforme a gravidez avança, as concentraçóes de progesterona apresentam marcadas mudanças que vão desde altos valores no início ( 9 a 29 dias) e em estágio mais avançado da prenhez (70-80 dias) até valores nấo detectáveis por volta do $40^{\circ}$ ao $60^{\circ}$ dia de prenhez e valores muito baixos trinta dias antes da parição. Em cutiaras (Myoprocta pratti Pocock, 1913), Rowlands et al. (1970) verificaram um aumento da concentração de progesterona no início da gestaçấo o qual foi assim mantido além da metade da prenhez, com um declínio no final da prenhez. De acordo com estes autores, as diferenças na quantificação de progesterona entre algumas espécies hystricomorphas se dão principalmente durante a prenhez, com relação aos níveis máximos encontrados e sua duração. Pérez e Baz (2006) descrevem valores para progesterona plasmática de 23 e $37.36 \mathrm{ng} / \mathrm{mL}$ em duas pacas no início da gestação.

A estimativa da idade gestacional por ultrassonografia é baseada na correlação entre tamanho e idade fetal (Varol et al. 2001). A mensuração do diâmetro biparietal (DBP) é rotineiramente utilizada durante o exame pré-natal em humanos (Torres 2008) e, para De Bulnes et al. (1998) e Abreu (2007) é um dos melhores e mais confiáveis parâmetros para estimar com elevada precisão a idade fetal em ovelhas e cabras. Outras medidas como circunferência abdominal, órbita ocular, e do coração, comprimento crânio caudal, diâmetro torácico, comprimento do fêmur, diâmetro dos placentomas, diâmetro do tronco fetal, também, são estimativas que se correlacionam com precisão com o crescimento fetal em cabras e ovelhas (Haibel e Perkins 1989; Dilmen et al. 2002; Lee et al. 2005; Abreu et al. 2007).

Em pacas, Oliveira et al. (2003) diagnosticaram gestação a partir do nono dia após a cobertura, pela visualização da vesícula embrionária e utilizaram medidas da área da placenta $\mathrm{e}$ da área cardíaca do feto, durante 129 e 89 dias respectivamente antes do parto, para estimar a idade gestacional.

Por serem as pacas de hábitos noturnos (Rengifo et al. 1996; Hosken e Silveira 2001), nem sempre é possível ao criador observar uma cópula, deduzir se houve fertilização e assim, estimar a data de pariçáo destes animais. Além disso, observa-se apenas o crescimento abdominal e intumescimento das mamas em pacas gestantes com bom escore corporal, a 
partir dos 90 dias de prenhez, há cerca de $2 / 3$ do período gestacional (Ribeiro e Zamora 2008).

Estabelecer critérios para um diagnóstico de gestação e determinar o período gestacional em uma fêmea é de fundamental importância na clínica veterinária, pois permite que o profissional da área e o criador estabeleçam um manejo reprodutivo adequado, possibilitando ainda a tomada de decisóes que afetem diretamente os índices de produtividade, evitando assim perdas econômicas.

Até o momento, a melhor forma de diagnosticar precocemente a gestação em pacas é por meio de ultrassonografia (Oliveira et al. 2003). Porém, nem sempre existe a disponibilidade para o produtor ou veterinário, do equipamento necessário para este fim. Por outro lado, existe uma escassez de trabalhos que possibilitam determinar o período gestacional desta espécie utilizando-se de medidas fetais. Assim sendo, é de primordial importância que se estabeleçam novos métodos de diagnostico de prenhez, que sejam mais acessíveis ao veterinário e ao criador e que se busque a aplicabilidade de novas medidas, como o diâmetro biparietal em fetos, que possibilitem determinar a idade gestacional da fêmea de paca, uma vez que ainda não foram testadas.

Com vistas ao exposto, este trabalho teve como objetivos descrever e caracterizar os tipos celulares presentes nos esfregaços vaginais de pacas, relatar as condiçôes de abertura da vulva e do muco vaginal aos 30, 60 e 90 dias de prenhez. Além disso, propôs-se determinar a concentração plasmática de progesterona e mensurar o diâmetro biparietal dos fetos, aos 60 e 90 dias de prenhez, avaliando a aplicabilidade desta medida, como forma de contribuir com o diagnóstico e o estabelecimento da idade gestacional nesta espécie.

\section{MATERIAL E MÉTODOS}

O trabalho foi desenvolvido na Fazenda Experimental Catuaba, da Universidade Federal do Acre, situada no município de Senador Guiomard/AC, km 30 rodovia BR - 364 (1004’ S e $\left.67^{\circ} 37^{\prime} \mathrm{W}\right)$. O clima da regiáo é do tipo amazônico equatorial quente e úmido com temperaturas anuais médias variando entre $24,5^{\circ} \mathrm{C}$ a $32^{\circ} \mathrm{C}$ (Acre, 2006).

Um total de 40 animais adultos foram utilizados, sendo 27 fêmeas e 13 machos, identificados por meio de microchips (AnimallTAG- KORTH - RFID, São Paulo - Brasil), os quais foram alocados em baias, na proporção de um macho para duas fêmeas, mas, em uma das baias, um macho foi posto com três fêmeas. As fêmeas eram comprovadamente pluríparas, e não gestantes quando foram postas com os machos. A alimentação dos animais foi composta de frutos, tubérculos e grãos produzidos na fazenda e colhidos na mata adjacente ao criatório. A água servida para banhos e ingestáo foi posta ad libitum e os dados foram coletados entre junho de 2008 a setembro de 2009.

\section{Esfregaços vaginais para preparação e coloração de lâminas para citologia}

Com os animais devidamente contidos, a colheita do material para citologia vaginal foi feita com swabs estéreis umedecidos com solução fisiológica, introduzidos cerca de seis centímetros no canal vaginal, após higienização adequada da vulva. Com o material obtido dos swabs, foram feitos esfregaços em lâminas histológicas identificadas com número do animal e data de coleta e imediatamente fixadas em álcool 95\% para, posteriormente, serem coradas pela técnica de Shorr e PAS e examinadas em microscópio de luz (Olympus CH30 - Japão, objetivas de 10x e 40x). Para se comprovar a presença de glicogênio no material dos esfregaços, a técnica de PAS era acrescida de amilase salivar, conforme sugerem Junqueira e Carneiro (1979). Para identificação dos tipos celulares foram contadas 100 células por lâmina, observandose a porcentagem dos tipos celulares presentes em cada lâmina. Os esfregaços vaginais foram feitos diariamente, pelas manhâs, até a identificação de espermatozoides nas lâminas quando se tinha então a confirmação da cobertura.

Aos 30, 60 e 90 dias após confirmação das coberturas, foram feitos esfregaços vaginais, como descritos anteriormente e, nessas ocasiôes, inspecionou-se, também, as condiçôes da vulva quanto ao seu fechamento ou abertura, presença e aspecto de muco vaginal.

$\mathrm{O}$ intervalo entre as coberturas e as pariçóes foi anotado de maneira que se pudesse estabelecer o período gestacional.

\section{Colheita de sangue para dosagem de progesterona plasmática}

Aos 60 e 90 dias após as coberturas foram colhidas amostras de cerca de $3 \mathrm{~mL}$ de sangue de todas as fêmeas, por venopunção da veia cefálica ou safena lateral ou safena medial, com scalps descartáveis $21 \mathrm{G}$ e seringas de $5 \mathrm{~mL}$ contendo EDTA, devidamente identificadas e mantidas sob refrigeração em caixas térmicas com gelo (por no máximo 3 horas) até que se procedesse a centrifugaçáo, feita a $900 \mathrm{~g}$ por 20 minutos. As amostras de plasma obtidas foram acondicionadas em frascos de polipropileno e armazenadas à temperatura de $-20^{\circ} \mathrm{C}$ até a realização das dosagens. As concentraçóes plasmáticas de progesterona foram determinadas de acordo com a técnica de radioimunoensaio empregando danazol, descrita por Knickerbocker et al. (1986), modificada por Carriere e Lee (1994).

\section{Exames ultrassonográficos}

Os exames ultrassonográficos foram realizados com equipamento de ultrassom para uso veterinário, com transdutor convexo de 7,5 MHZ (Aloka, modelo SSD-500v 
- Aloka Co. Tókio, Japão) aos 30 dias após as coberturas para confirmação da prenhez e aos 60 e 90 dias após as coberturas, para que se mensurasse o DPB fetal, por ser este considerado na literatura um dos melhores e mais confiáveis parâmetros para estimar com elevada precisão a idade fetal em animais (De Bulnes et al. 1998; Abreu 2007), além de ser rotineiramente usada em humanos (Torres 2008).

A opção de se tomar a medida do DBP apenas nestes dois períodos gestacionais, assim como as coletas de sangue para quantificação da progesterona, foi feita para minimizar a manipulação das fêmeas prenhes, uma vez que, animais silvestres são altamente susceptíveis ao estresse por manipulação e eventuais abortamentos por este fator (Ribeiro e Zamora 2008).

Para tanto, cada fêmea foi devidamente contida em puçá e posta em decúbito dorsal, sem uso de tranquilizantes ou de anestésicos. Não se efetuou tricotomia na área abdominal trabalhada, por ser uma regiáo com poucos pelos, porém, utilizou-se gel apropriado para exame ultrassonográfico (Carbogel Ind. e Com. Ltda. São Paulo, Brasil), como meio de contato do transdutor com a pele.

Inicialmente posicionava-se o transdutor cerca de dois centímetros cranialmente ao par de mamas inguinais, para o procedimento de varredura longitudinal da regiáo abdominal caudal e cavidade pélvica. Na sequência, deslocava-se o transdutor cranial e lateralmente à linha alba por aproximadamente $12 \mathrm{~cm}$, passando-se pela porção média do abdômen e finalizando na porção cranial até o encontro do crânio fetal, identificado pela imagem em tempo real. A partir daí, quando as órbitas foram identificadas e a imagem congelada, mensurou-se em corte sagital o DBP que correspondeu à medida externa da região mais larga do crânio fetal (Figura 1).

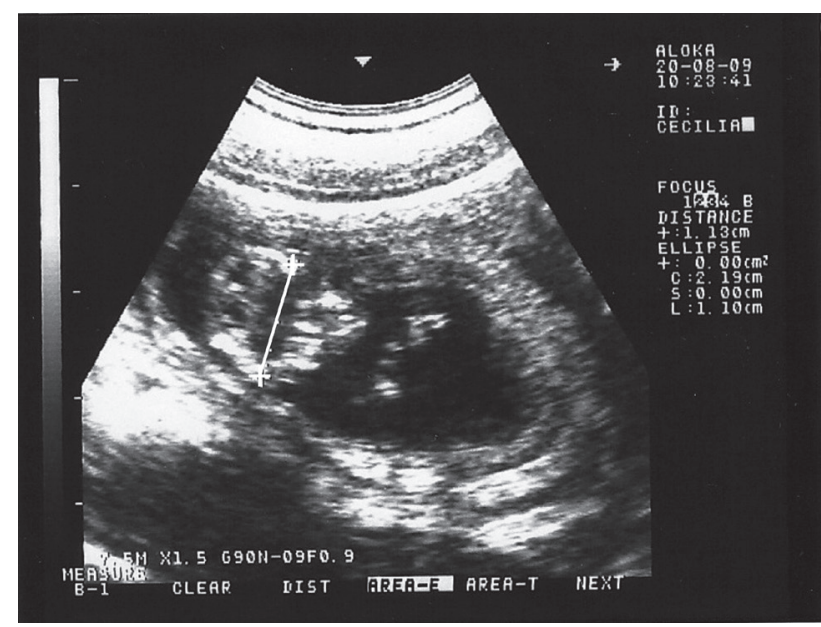

Figura 1 - Imagem ultrassonográfica de feto de Cuniculus paca, 60 dias pós concepção. DBP $=1,10 \mathrm{~cm}$.

\section{Análises Estatísticas}

Todos os dados obtidos foram analisados através de procedimentos de estatística descritiva. Com relação aos tipos celulares encontrados foram efetuados percentuais médios e desvio-padrão e, para comparação entre médias, o teste $\mathrm{t}$ de Student $(\mathrm{p}<0,05)$; Os dados relativos à concentração de progesterona aos 60 e 90 dias de prenhez, foram expressos por médias e respectivos desvios-padrão e pelos valores absolutos da máxima e da mínima concentração. As condiçôes de muco e do vestíbulo vaginal foram dadas em percentuais. A medida do DBP aos 60 e 90 dias é apresentada em forma de média, desvio-padrão e os dados obtidos foram submetidos ao teste de Correlação de Pearson, adotando-se valor de $\mathrm{p}<0,05$; Para isto, utilizaram-se os softwares Microsoft ${ }^{\oplus}$ Office Excel 2000 e SAS - Statistical Analysis System (SAS, 2003).

\section{Aspectos Legais}

Este trabalho foi realizado com autorização do Ministério do Meio Ambiente-MMA, Instituto Chico Mendes de Conservação da Biodiversidade/SISBIO, sob número 24669-1 (Autorização para atividades com finalidade científica).

\section{RESULTADOS E DISCUSSÃO}

Neste estudo, pela citologia vaginal gestacional, constataram-se padróes celulares particularmente exclusivos, com a presença de tipos celulares diferenciados, somente observados em situaçóes específicas.

As células intermediárias apareceram frequentemente na forma de células naviculares (Figura 2).

Para Gompel e Koss (1997) em mulheres, durante a gravidez a quantidade elevada do glicogênio caracteriza a célula navicular. Esta tem forma de barco, com núcleo deslocado pelo

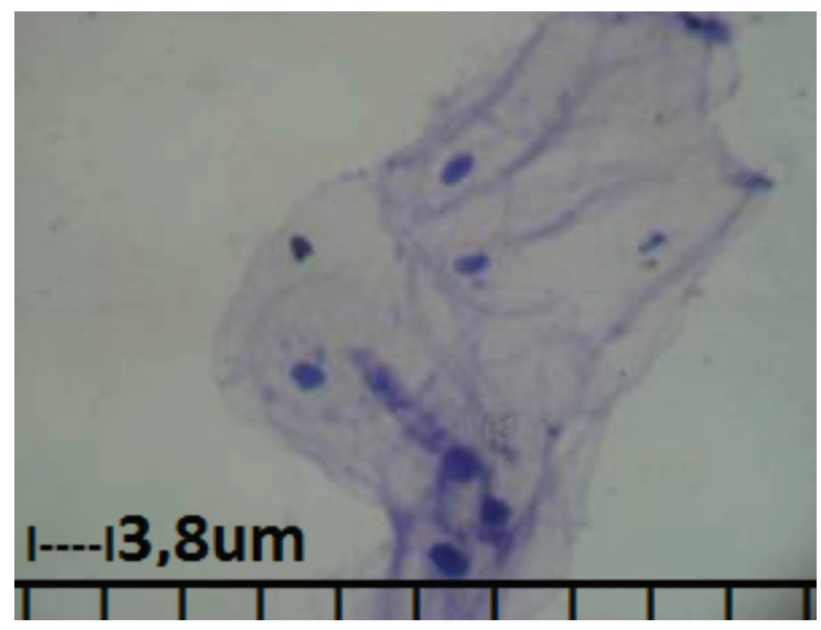

Figura 2 - Fotomicrografia de esfregaço vaginal de Cuniculus paca. Células naviculares, Coloração PAS + amilase, $400 \mathrm{X}$. Barra 3,8 $\mu \mathrm{m}$. 
glicogênio para periferia da célula. Nos outros tipos celulares, não se observou mudanças de padrão.

As células endocervicais (Figura 3) encontradas, raramente observadas em esfregaços de epitélios vaginais de um ciclo estral, mostraram-se muito ativas na produção de muco e estiveram presentes em $73,9 \%$ e em $69 \%$ das lâminas aos 60 e 90 dias prenhez respectivamente. Estes resultados conferem com as descriçôes da citologia esfoliativa vaginal em mulheres grávidas (Gompel e Koss 1997; Floriano et al. (2007). e em fêmeas prenhas de catetos (Tayassu tajacu Linnaeus, 1758) descritas por Mayor et al. (2004).

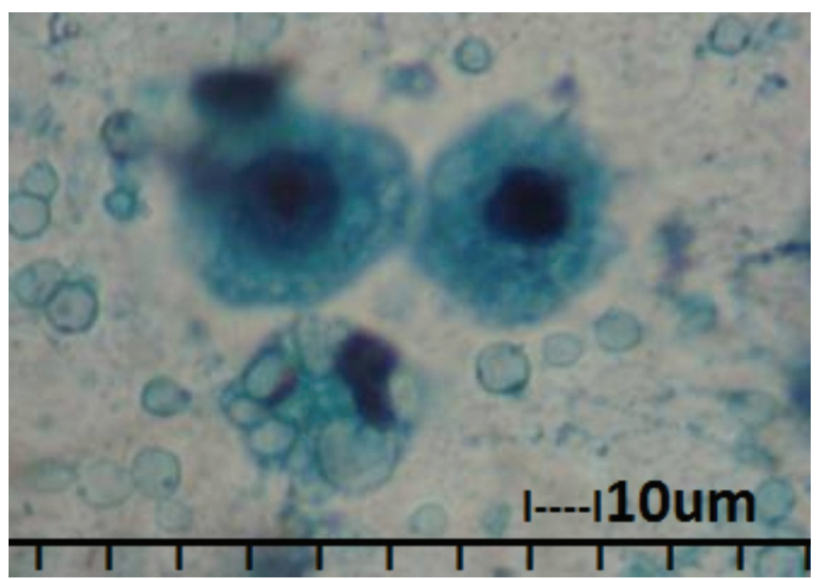

Figura 3 - Fotomicrografia de esfregaço vaginal de Cuniculus paca. Células endocervicais, Coloração Shorr 400 X. Barra $10 \mu \mathrm{m}$.

A abundância de muco produzido pelas células endocervicais encontradas neste trabalho, provavelmente favoreceu a formação do tampão mucoso gestacional, conforme relata Hafez (2004).

Em lâminas coradas pela técnica histoquímica PAS adicionado de amilase, as células endocervicais coravam-se em magenta, estavam repletas de mucina e provavelmente, continham glicogênio. Além disso, foram encontrados vacúolos isolados, corados em azul tênue, supostamente exocitados por estas células. Este achado é corroborado por Gompel e Koss (1997) quando afirmam que a carga glicogênica aumenta sob a ação da progesterona e é máxima durante a gestação. Os autores chamam a atenção para o fato de que a gestação em mulheres pode se desenvolver com a ausência de qualquer imagem citológica característica.

Ayen et al. (2002) verificando as mudanças histológicas da parede vaginal de vacas em diferentes estágios de prenhez, também evidenciaram uma marcada diferença entre o nono mês e os restantes. A partir do $8^{\circ}$ mês, células colunares secretórias foram observadas no epitélio e aumentaram em quantidade até o nono mês de prenhez. Todas estas alteraçôes, de acordo com os autores, se devem a mudanças hormonais nos diferentes estágios de prenhez. Neste trabalho, as células secretoras puderam ser vistas a partir do segundo mês de gestação (correspondente aproximadamente ao segundo terço da prenhez).

Em aproximadamente $40 \%$ das lâminas, foram observados muitos núcleos nus no material vaginal coletado aos 60 e 90 dias de prenhez. Este fenômeno de citólise, conforme Gompel e Koss (1997) atingem particularmente células intermediárias e é resultado da digestão do glicogênio por lactobacilos deixando os esfregaços caracterizarem-se por exibir núcleos nus e detritos celulares. De acordo com Carvalho (2002) os núcleos nus se observam principalmente na fase pós ovulatória e na gravidez.

Aos 30 dias de prenhez, as células intermediárias e superficiais aparecem praticamente na mesma proporção nos esfregaços e, à primeira vista, em um padráo muito semelhante ao proestro nesta espécie, evidenciando intensa estrogenia. Entretanto, as células intermediárias na forma navicular, que não são comuns em um ciclo estral estâo presentes em $75 \%$ das lâminas, compondo no mínimo $30 \%$ dos tipos celulares encontrados e fazem a diferença entre estas duas fases.

Aos 60 dias de prenhez, 73,9\% das fêmeas apresentaram em seus esfregaços células endocervicais, compondo no mínimo 5\% do total de células encontradas. As células intermediárias, do tipo navicular, estão presentes em 47,8\% das lâminas. Em seis fêmeas, 40 a $60 \%$ das células eram do tipo superficial, muitas das quais anucleadas, sugestivo de fase estrogênica cíclica.

Aos 90 dias de prenhez, 69\% das lâminas continham de 10 a $60 \%$ de células endocervicais e células naviculares em 39,1\% das lâminas. Também, neste período gestacional, cinco fêmeas mostraram tipos celulares característicos de intensa estrogenia, compatíveis com um padrão de proestro.

Os valores descritos para os tipos de células parabasais, intermediárias, naviculares e endocervicais não diferiram ( $\mathrm{p}$ > $0,05)$ nos períodos gestacionais de 60 e 90 dias, o que indica uma uniformidade nos padróes celulares do epitélio vaginal de pacas durante estes períodos gestacionais citados. Entretanto, diferiram ( $p<0,05)$, os tipos celulares naviculares e superficiais aos 30 dias dos demais períodos (Tabela 1).

O padrão celular estrogênico, sugerindo atividade folicular, encontrado na citologia esfoliativa vaginal aos 30 dias de prenhez, assim como em seis e em cinco fêmeas aos 60 e aos 90 dias de prenhez respectivamente, provavelmente se deve ao fato de que fêmeas de paca prenha, de acordo com Matamoros (1981) e Pérez e Baz (2006) tenham em seus ovários, folículos em diferentes fases do seu desenvolvimento, entre os quais alguns poderão luteinizar ou serão responsáveis pelo desencadeamento de um cio pós parto (Matamoros 1981). Em porcos espinhos (Hytrix afriaeaustralis Linnaeus, 1758) Van 
Tabela 1 - Tipos celulares em esfregaço vaginal de pacas (Cuniculus paca) aos 30, 60 e 90 dias de prenhez (média \pm desvio padrão dos percentuais). Rio Branco, 2010

\begin{tabular}{cccccc}
\hline Período & C P (\%) & C I (\%) & C N (\%) & C S (\%) & C E (\%) \\
\hline 30 dias & & $25( \pm 11,2) \mathrm{a}$ & $25( \pm 15) \mathrm{a}$ & $47,5( \pm 4,3) \mathrm{a}$ & \\
60 dias & $14,3( \pm 12,3) \mathrm{a}$ & $29,7( \pm 13,4) \mathrm{a}$ & $9,5( \pm 12,2) \mathrm{b}$ & $21,0( \pm 17,3) \mathrm{b}$ & $25,2( \pm 22,4) \mathrm{a}$ \\
90 dias & $12,8( \pm 14,3) \mathrm{a}$ & $24,1( \pm 12,3) \mathrm{a}$ & $13,9( \pm 20,6) \mathrm{b}$ & $20,9( \pm 20,4) \mathrm{b}$ & $27,3( \pm 23,4) \mathrm{a}$ \\
\hline
\end{tabular}

$C P=$ células parabasais, $C I=$ células intermediárias, $C$. $N=$ células naviculares, $C$ S = células superficiais, $C E=$ células endocervicais. Médias de tratamento seguidas de letras diferentes (nas colunas) diferem significativamente pelo teste $t-S$ Student $(p<0,05)$.

Aarde e Skinner (1986) e em cutiaras (Rowlands et al. 1970) encontraram atividade folicular em fêmeas prenhes durante todo o período gestacional e observaram que estas estruturas sofriam luteinização, formando os corpus lúteos acessórios importantes para suplementar a progesterona necessária a manutenção da prenhez. Uma grande quantidade de corpo lúteo acessório proveniente de folículos em desenvolvimento, também foi observada em pacas prenhes por Matamoros (1981).

O padrão celular estrogênico observado em fêmeas de pacas prenhes encontradas neste trabalho, também foi observado por Mayor et al. (2004) em exames histológicos de ovários de pecaris (Tayassu tajacu Linnaeus, 1758) gestantes. Segundo estes autores, existem crescimentos de grupos de folículos com estabelecimento de dominância e que o crescimento folicular responsável pela síntese ovariana de estrógenos, poderia justificar a alteração do padrão celular que ocorre no epitélio vaginal destas fêmeas, mesmo durante a gestaçáo. De acordo com Thomas e Dobson (1989) de 8 a $10 \%$ de vacas gestantes, também apresentam sinais de estro em plena gestação.

No criatório onde a pesquisa foi realizada, uma fêmea pariu uma cria com 900 gramas de peso e outra, uma com 800 gramas. Aos 30 e 45 dias pós parto, as duas fêmeas voltaram parir uma cria cada. Este episódio, sugere ser possível ocorrer desenvolvimento folicular e cio fértil com cobertura, em pacas no período gestacional, fato este corroborado pelos achados citológicos neste experimento e pelos trabalhos de Mayor et al. (2004) e Thomas e Dobson (1989).

Aos 30 dias de prenhez, o muco vaginal apresentou-se cristalino e pouco viscoso em todas as fêmeas. $\mathrm{O}$ vestíbulo vulvar em metade delas apresentava-se aberto.

Aos 60 dias de prenhez, $53 \%$ das fêmeas apresentaram vestíbulo vaginal fechado e $47 \%$ aberto. Aproximadamente, os mesmos números ocorreram aos 90 dias, isto é, $50 \%$ das fêmeas permaneceram com o vestíbulo vaginal aberto. Estas constataçôes diferem das de Weir e Rowlands (1973) os quais relataram que os caviomorfos (Grupo de roedores que apresentam quatro molares de cada lado da mandíbula), com exceção do ratâo-do-banhado (Myocastor coypus Molina, 1782 ), possuem uma membrana vaginal oclusa formada em razão da hiperplasia de células epiteliais, abrindo-se somente durante o estro ou o parto. Diferem ainda de Hosken e Silveira (2001) e Nogueira et al. (2005) segundo os quais, a membrana vaginal da paca geralmente permanece aberta no cio e fechada nos outros estágios reprodutivos.

Matamoros e Pashov (1984) também observaram pacas com vestíbulo vaginal aberto durante a prenhez. Esta situação durante a prenhez em pacas, provavelmente se dá devido às variaçôes hormonais (relação progesterona / estrógenos) que ocorrem em roedores e constatados em porco espinho, coelhos (Oryctolagos cunniculus Linnaeus, 1758) e chinchilas durante a gestação (Van Aarde e Potgieter 1986; Van Aarde e Skinner 1986; Holt 1989; Busso et al. 2007).

Ao se efetuar os swabs vaginais constatou-se que $26 \%$ e 30\% das fêmeas estudadas, respectivamente, aos 60 e 90 dias de prenhez apresentaram muco mais viscoso ou espesso, provavelmente, devido à ação da progesterona; essa característica do muco confere maior proteção ao ambiente uterino na prenhez. No restante dos animais o muco apresentava-se fluido e cristalino. Estes resultados diferem, portanto em parte, dos encontrados em catetos por Mayor et al. (2004) que verificaram uma grande quantidade de muco espesso e viscoso em fêmeas prenhes.

As características do muco encontrado aos 30,60 e 90 dias de prenhes, estão de acordo com os achados citológicos nestas mesmas fases de período gestacional, uma vez que, aos 30 dias, o epitélio vaginal apresentou fortes características de estrogenia, o que provavelmente tenha levado a formação de um muco mais fluido e menos viscoso, enquanto que aos 60 e 90 dias de prenhez com a intensa produçáo de muco observada pelas células endocervicais é de se esperar um muco mais viscoso. Além disso, as variaçóes hormonais sofridas pelo epitélio vaginal ao longo da prenhez, conforme observado em outros roedores (Van Aarde e Potgieter 1986; Van Aarde e Skinner 1986; Holt 1989; Busso et al. 2007), podem ter corroborado para este fato.

Os resultados da determinação da concentração plasmática de progesterona demonstraram que $94 \%$ e $88,8 \%$ das fêmeas aos 60 e 90 dias de prenhez respectivamente, tinham valores inferiores a $1 \mathrm{ng} / \mathrm{mL}$. Os valores máximos encontrados foram 3,03 e $3,55 \mathrm{ng} / \mathrm{mL}$ aos 60 e 90 dias de prenhez respectivamente, enquanto que o mínimo foi $0,31 \mathrm{ng} / \mathrm{mL}$ para os dois períodos. As médias e desvios padrão foram 
$0,3765 \pm 0,1454 \mathrm{ng} / \mathrm{mL}$ e $0,3677 \pm 0,1702 \mathrm{ng} / \mathrm{mL}$ aos 60 e 90 dias de prenhez, respectivamente. $\mathrm{Na}$ análise de consistência dos valores determinados para concentração plasmática de progesterona, os dois máximos $(3,03$ e 3,55 ng/mL), foram excluídos dos cálculos estatísticos por serem considerados outliers, ou seja, fora do intervalo de três desvios padrão. Desconhece-se a razáo do grande afastamento desses valores nos dados encontrados para progesterona nestes períodos gestacionais.

De acordo com Jainuden et al (2004) a quantificação da progesterona, tem sido amplamente utilizada para diagnóstico da gestação em animais domésticos e que embora seja um método não específico para a prenhez, esta pode ser utilizada em razão da persistência do corpo lúteo durante o início da gestação em todos os animais domésticos. Normalmente, a amostra (sangue ou leite) é coletada um ciclo estral após a inseminação ou cobertura, ou seja, 22 a 24 dias em bovinos e bubalinos, 16 a 18 dias em ovinos, 18 a 21 dias em caprinos, 16 a 22 dias em equinos e 21 dias em suínos. Naqueles períodos, o nível de progesterona é baixo no animal não prenhe e alto no animal prenhe.

Neste trabalho, as dosagens de progesterona só foram efetuadas no segundo terço gestacional. As lacunas causadas pela falta de amostragem no primeiro e último terço gestacional, dificultaram o entendimento sobre o comportamento da concentração plasmática de progesterona ao longo da gestaçáo de pacas e, por conseguinte, seu papel no diagnóstico da gestação nestes animais. Porém, os níveis mínimos detectáveis deste hormônio na maioria das fêmeas, durante os períodos gestacionais pesquisados (60 e 90 dias de prenhez, segundo terço da gestação), são compatíveis aos encontrados no segundo terço da gestação em camundongos (Swiss mice Linnaeus,1758) por McComarck e Greenwald (1974) e chinchilas (Tam 1970; Gromadzka-Ostrowska 1985; Busso 2007), quando a concentração plasmática de progesterona também encontrava- se a níveis mínimos detectáveis nestas espécies. Andreazzi et al. (2004) observaram que em coelhas gestantes, a concentração de progesterona aumenta linearmente até o décimo dia da gestação, atingindo os níveis máximos que começam entáo a cair cerca de 10 dias antes do parto. Em cutiaras os níveis de progesterona plasmática começam a decair no segundo terço gestacional, até atingir níveis mínimos próximos à parição (Rowlands et al. 1970). Estes últimos autores relatam que nas espécies hystricomorphas, as diferenças entre níveis mínimos e máximos de progesterona e sua duraçâo se dão principalmente durante a prenhez. Pérez e Baz (2006) relatam que em duas pacas, logo após a implantação dos embrióes, os níveis de progesterona atingiram 23 e $37,36 \mathrm{ng} / \mathrm{mL}$. No entanto, não acompanharam o desenvolvimento da gestação nestes animais e, por conseguinte, as possíveis modificaçôes nos níveis de progesterona plasmática ao longo desta fase reprodutiva.

As avaliaçôes ultrassonográficas levadas a efeito aos 30 dias de prenhez não possibilitaram determinar o DBP dos fetos, embora permitissem a visualização da vesícula embrionária e o saco gestacional. Este parâmetro foi bem estabelecido aos 60 e 90 dias de prenhez (Figura 1)

Os valores das medidas dos DBP em $\mathrm{cm}$ (média \pm desvio padrão) aos 60 e 90 dias de prenhez e o incremento observado foram $1,25 \pm 0,16$ e 2,34 $\pm 0,25,1,09 \mathrm{~cm} \pm 0,30$, respectivamente. Os valores mínimos e máximos registrados aos 60 dias foram $1,04 \mathrm{~cm}$ e $1,57 \mathrm{~cm}$ e aos 90 dias $1,75 \mathrm{~cm}$ e $2,74 \mathrm{~cm}$. O maior incremento observado no período de 30 dias foi de $1,51 \mathrm{~cm}$ e o menor de $0,49 \mathrm{~cm}$. Valores dos DBP aos 60 e 90 dias são diferentes $(\mathrm{p}<0,05)$.

Os DBP dos fetos aos 90 dias de prenhez náo mostraram correlação $(r=0)$ com os de 60 dias, sugerindo, portanto, que o maior diâmetro encontrado aos 60 dias, necessariamente, não será o maior diâmetro encontrado aos 90 dias.

Das 27 fêmeas trabalhadas, apenas uma não levou a gestação a termo, pois abortou logo após o manuseio aos 90 dias de prenhez. O período gestacional das fêmeas restantes durou em média 152,33 \pm 0,47 dias e é similar aos de Rengifo et al. (1996) 145 a 155 dias; Guimaráes et al. (2008) 148,6 + 4,8 dias e Ribeiro e Zamora (2008)

\section{CONCLUSÕES}

Os resultados encontrados demonstram que a citologia esfoliativa vaginal, bem como o diâmetro biparietal, podem ser utilizados como parâmetros para diagnóstico de prenhez e determinação da idade gestacional em pacas. Entretanto, apenas o exame do muco ou as condiçóes em que se encontram o vestíbulo vaginal destes animais não oferecem confiabilidade para estes propósitos. Por outro lado, para que se possam utilizar dados da quantificação de progesterona como fator de diagnóstico de prenhez em pacas, mais estudos devem ser efetuados durante todo o período gestacional.

\section{AGRADECIMENTOS}

Agradecemos ao Governo do Estado do Acre nas pessoas do Secretário de Agropecuária, Sr. Mauro Ribeiro e o Dr. Edson Alves de Araújo, e ao Laboratório de Farmacologia da Reprodução da UNESP/Botucatu - São Paulo na pessoa do Dr. Ciro Moraes Barros na realização deste trabalho.

\section{BIBLIOGRAFIA CITADA}

Acre. Governo do Estado do Acre, 2006. Programa Estadual de Zoneamento Ecológico-Econômico do Estado do Acre. Zoneamento Ecológico-Econômico do Acre Fase II: documento sintese -Escala 1:250.000. SEMA. Rio Branco, Acre. 356 pp. 
Abreu, D.; Almeida, J.C.; Silva, S.; Azevedo, J.; Fontes, P.; Simôes, J. 2007. Estimativa da idade fetal por ultra-sonografia em cabras da raça Serrana. REDVET- Revista electrónica de Veterinaria, 8:1-6. (http://redalyc.uaemex.mx/redalyc/pdf/636/63614239004.pdf). Acesso em: 14/05/2010.

Andreazzi, M.A.; Scapinello, C.; Moraes, G.V.; Faria , H.G.;Aoki, E.e.; Michelan, A.C. 2004. Avaliação de metabólitos lipídicos e hormônios esteroides em soro de coelhas alimentadas com ração contendo diferentes fontes de óleos vegetais. Acta Scientiarum Animal Sciences, 26: 359-365.

Ayen, E.; Hasanzadeh, S.H.; Abdollah-Vand, M. 2002. Histological changes of the vaginal wall during different stages of pregnancy, oestrus and di-oestrus in cow. Journal of Veterinary Research, 57: 15-19.

Bastos, L. V.; Guimarães, D.A.; Luz-Ramos,R.S.; Ferreira, A.C.S; Ohashi, O.M.. 2003 Aspectos da citologia vaginal durante o ciclo estral de Agouti paca criada em cativeiro. Revista Brasileira de Reprodução Animal, 27: 294 - 295.

Busso, J. M.; Ponzio, M. F.; Cuneo, M. F.; Ruiz, R.D. 2007. Noninvasive monitoring of ovarian endocrine activity in the chinchilla (Chinchilla lanigera). Endocrinology, 150: 288-297.

Carriere, P.D.; Lee, B. 1994. Direct radioimmunoassay of progesterone in bovine plasma using danazol (17-alpha-2,4pregnadien-20-yno(2,3-d)isoxazol-17-ol) as a displacing agent. Canadian Journal of Veterinary Research, 58: 230-233.

Carvalho, G. 2002. Achados Citológicos nas Diferentes Circunstâncias Obstétricas, p.117-120. In: Carvalho, G.(Ed.). Citologia do Trato Genital Feminino. 4a Edição. Atheneu, São Paulo, São Paulo.

De Bulnes, A.G.; Moreno, J.S.; Sebastian, A.L. 1998. Estimation of fetal development in Manchega dairy ewes by transrectal ultrasonographic measurements. Small Ruminant Research, 27: $243-250$.

Diehl, J.R.; B. N. Day, B.N. 1973. Utilization of frozen sections with the vaginal biopsy technique for early pregnancy diagnosis in swine. Journal Animal Science, 37: 114-117.

Dilmen, G.; Koktenes, A.; Turhan, T.O.; Tez, S. 2002. Growth of the fetal lens and orbit. International Journal Gynecology Obstetrics, 76: 267-271.

Floriano, M. I.; Araújo, C. S. A.; Ribeiro, M. A. 2007. Conhecimento sobre fatores de risco associados ao câncer do colo uterino em idosas em Umuarama-PR. Arquivos Ciências da Saúde Unipar, 11: 199-203.

Gompel, C.; Koss, L. 1997. Citologia do Aparelho Genital Feminino p.39 - 48. In: Gompel, C.; Koss, L. (Eds.). Citologia Ginecologia e suas Base Anatomoclínicas. Manole, São Paulo, São Paulo.

Gromadzka-Ostrowska, B.; Zalewska, E.; Szylarska-Gozdz. 1985. Peripheral plasma progesterone concentration and hematological indices during normal pregnancy of Chinchillas (Chinchilla laniger). Comparative Biochemistry and Physiology. Parte A 82: 661-665.

Guimarães, D.A.; Bastos, L.V.; Ferreira, A.C.S.; Luz-Ramos, R.S. Ohashi, O. M.; Ribeiro, H.L. 2008. Características reprodutivas da paca fêmea (Agouti paca) criada em cativeiro. Acta Amazonica,38: 531-538.
Hafez, E.S.E. 2004. Anatomia Funcional da Reproduçáo Feminina. P.13-29: In: Hafez, E. S. E. (Ed). Reprodução Animal. Manole, São Paulo, São Paulo.

Haibel, G.K.; Perkins, N.R.; Lidl, G.M. 1989. Breed differences in biparietal diameters of second trimester Toggenburg, Nubian, Angora goats fetuses. Theriogenology, 32: 827 - 835 .

Holt, J.A.1989. Regulation of progesterone production in the rabbit corpus luteum. Biology of reproduction, 40: 201- 208.

Hosken, F. M.; Silveira, A. C. 2001. Criação de pacas. Coleção Animais Silvestres. v.3. Aprenda Fácil, Viçosa, Minas Gerais, 206 pp.

IBAMA. Instituto Nacional do Meio Ambiente e dos Recursos Naturais Renováveis. Disponível em: http://www.ibama.org.br. Acesso em: 21/03/ 2003.

Jainudeen, M.R.; Wahid, H.; Hafez, E. S.E. 2004. Indução da ovulação, Produção e transferência de Embriōes, p.409 - 434. In: Hafez, E.S.E.; Hafez, B. (Eds.). Reprodução Animal. Manole, São Paulo, São Paulo.

Junqueira, L.C.; Carneiro, J. 1979. Histoquímica e Citoquímica, p. 20-29. In: Junqueira L.C.; Carneiro, J. Histologia Básica. Guanabara Koogan, Rio de Janeiro, Rio de Janeiro.

Knickerbocker J.J, Thatcher, W.W, Bazer F.W, Drost M, Barron, D.H, Ficher K.B, Roberts R.M. 1986. Protein secreted by Day 16 to 18 bovine conceptuses extends corpus luteum function in cows. Journal of Reproduction Fertility, 77: 381-391.

Lee, Y.; Lee, O.; Cho, J.; Shin, H.; Choi, Y.; Shim, Y.; Choi, W.; Shin, H.; Lee, D.; Lee, G.; Shin, S. 2005. Ultrasonic measurement of fetal parameters for estimation of gestational age Korean black goats. Journal of Veterinary Medical Science, 67: 497-502.

Matamoros, Y. 1981. Anatomia e histologia del sistema reprodutor del tepezcuinte (Cuniculus paca). Revista Biologia Tropical, 29: 155-156.

Matamoros, Y. 1982. Notas sobre la biologia del tepezcuinte, Cuniculus paca, Brisson (Rodentia: Dasyproctidae) em cativerio. Brenesia, 20:71-82.

Matamoros, Y.; Paschov, B. 1984.Ciclo estral del tepezcuite (Cuniculus paca, Brisson), em cautiveiro. Brenesia, 22: 249-260.

Mayor, P.; Jori, F.; López-Bejar, M. 2004. Anatomicohistological characteristics of the tubular of genital organs of the female Collared Pecary (Tayassu tajacu) From North - Eastern Amazonia. Anatomy Histology Embriology, 33: 65-74.

McComarck, J.T.; Greenwald, G.S. 1974. Progesterone and oestradiol $17 \beta$ concentrations in the peripheral plasma during pregnancy in the mouse. Journal of Endocrinology, 62: 101-107.

Mittermeier, R.A., Schwarz, M.; Ayres, J.M. 1992. A new species of marmoset, genus Callithrix Erxleben, 1777 (Callitrichidae, Primates) from the Rio Maues region, state of Amazonas, central Brazilian Amazonia. Goeldiana Zoologia, 14:1-17.

Moreira, J.R.; Macdonald, D.W. 1997. Técnicas de manejo de capivaras e outros grandes roedores na Amazônia, p. 186-213. In: Vallades-Pádua, C.; Bodmer, R. E; Wellen J. L. Manejo e Conservação de Vida Silvestre no Brasil. Sociedade Civil Mamirauá, Belém, Pará. 
Nogueira, T.M.R.; Toniollo, G.H.; Giannoni, M.L.2005. Estrous cicle colpocitology in captive pacas (Agouti paca Linnaeus, 1766). Ars Veterinária, 21: 209-214.

Nogueira-Filho, S.L.G.; Nogueira, S.S. 1999. Criação de Pacas (Agouti paca). Piracicaba, São Paulo. 60 pp.

Oliveira, F.S.; Machado, R.F.; Canola J.C. 2003. Real time B- mode ultrasound in pacas pregnancy (Agouti paca, Linnaeus, 1776). Brazilian Journal of Veterinary Research and Animal Science, 40: 73-78.

Pérez, R. C. M.; Baz, E. A. C. 2006. Actividad ovárica del tepezcuintle Agouti paca (Rodentia: Agoutidae) en cautiverio. Revista de Biología Tropical, 54: 903-912.

Porto R.R.M.; Cavalcante, T.V.; Dias, F.E.F.; Rocha, J.M.N.; Souza, J.A.T. 2007. Perfil citológico vaginal de ovelhas da raça Santa Inês no acompanhamento do ciclo estral. Ciência Animal Brasileira, 8: 521-527.

Raposo, R.S., L.D.M. Silva, R.N.B. Lobo, V.J.F.Freitas e F.E.F. Dias. 2000. Comparação da citologia vaginal de cabras cíclicas e gestantes da raça Saanen. Revista Cientifica de Produção Animal, 2: 12-16.

Rengifo, M.E.; Navarro, D.T.; Urrunaga, A.B.; Vásquez, W.F.; Aspajo, F.V. 1996. - Crianza Familiar del Majaz o Paca (Agouti paca) en la Amazonia. Mirigraf S.R.L., Tratado de Cooperacion Amazonica-Secretaria pró tempore \# 48, Lima, Peru. 45 pp.

Ribeiro, V.M.F ; Zamora, L.M. 2008. Pacas e capivaras criação em cativeiro com ambientação natural. Editora Bagaço, Rio Branco, AC. 48 pp.

Rowlands, I.W.; Tam,W.H.; Kleiman, D.G. 1970. Histological and Biochemichal Studies on the ovary and of progesterone levels in the systemic blood of the green acouchi (Myoprocta pratti). Journal Reproduction Fertility, 22: 533-545.
SAS INSTITUTE 2003. Statistical Analisys System: user's guide. Version 9.1.

Tam, W.H. 1970. A comparative study of the production of progesterone by various hystricomorph rodents, Journal Endocrinology. 48: 18-19.

Thomas, I.; Dobson, H. 1989. Oestrus during pregnancy in the cow. The Veterinary Record, 124: 387-390.

Torres, C.A. 2008. Estimativa da idade gestacional por ultra-sonografia no primeiro terço da gestação em cabras Saanen. Dissertaçáo de Mestrado, Universidade Estadual do Ceará, Fortaleza, Ceará. $54 \mathrm{pp}$.

Van Aarde, R.J.; Potgieter, H.C.1986. Circulating progesterone, progesterone-binding proteins and oestradiol $17 \beta$ concentrations in the pregnant cape porcupine Hystrix africaeaustralis. Journals of Reproduction and Fertility, 76: 561-567.

Van Aarde, R.J.; Skinner, J. D. 1986. Functional anatomy of the ovaries of pregnant and lactating Cape porcupine, Hystrix africaeaustralis. Journals of Reproduction and Fertility, 76: 553 559.

Varol, F.; Saltik, A.; Kaplan, P.B. 2001. Evaluation of gestational age based of ultrasound fetal growth measurements. Yonsei Medical Journal, 42: 299-303.

Weir, B.; Rolands, I.W. 1973. Reproductive strategies of mammals. Acta Review Ecology Systemic, 4: 139-163.

Recebido em: 05/04/2011

Aceito em: 11/10/2011 
